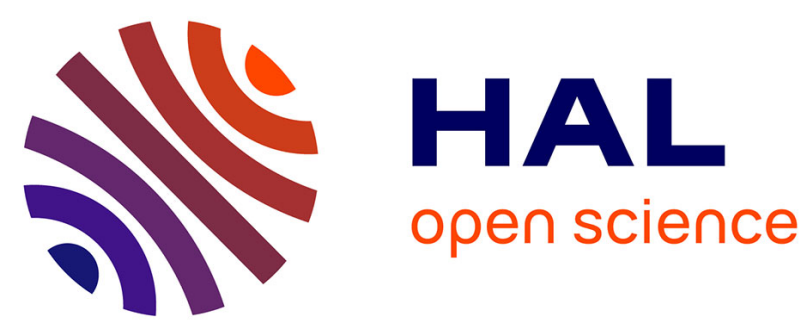

\title{
Robust Control Law Strategy Based on High Order Sliding Mode: Towards a Muscle Control
}

\author{
Samer Mohammed, Philippe Fraisse, David Guiraud, Philippe Poignet,
} Hassan El Makssoud

\section{- To cite this version:}

Samer Mohammed, Philippe Fraisse, David Guiraud, Philippe Poignet, Hassan El Makssoud. Robust Control Law Strategy Based on High Order Sliding Mode: Towards a Muscle Control. IROS'05: International Conference on Intelligent Robots \& Systems, Aug 2005, Edmonton (Canada), pp.28822887. lirmm-00106501

\section{HAL Id: lirmm-00106501 https://hal-lirmm.ccsd.cnrs.fr/lirmm-00106501}

Submitted on 16 Oct 2006

HAL is a multi-disciplinary open access archive for the deposit and dissemination of scientific research documents, whether they are published or not. The documents may come from teaching and research institutions in France or abroad, or from public or private research centers.
L'archive ouverte pluridisciplinaire HAL, est destinée au dépôt et à la diffusion de documents scientifiques de niveau recherche, publiés ou non, émanant des établissements d'enseignement et de recherche français ou étrangers, des laboratoires publics ou privés. 


\title{
Robust control law strategy based on High Order Sliding Mode: towards a muscle control.
}

\author{
Samer MOHAMMED, Philippe FRAISSE, David GUIRAUD, Philippe POIGNET and Hassan El MAKSSOUD \\ DEMAR Project - Department of Robotics \\ LIRMM \\ CNRS - INRIA - University of Montpellier II \\ 161 Rue Ada, 34392 Montpellier Cedex 5, France \\ mohammed@lirmm.fr,fraisse@lirmm.fr
}

\begin{abstract}
Functional electrical stimulation (FES) is used to excite paralysed muscles that would otherwise be uncontrollable by paraplegic patients. Consequently, the patient could recover partially some of lower limb functions improving the cardiovascular system, increasing oxygen uptake and bettering the whole quality of life. In this paper, we apply a control design based on a Higher Order Sliding Mode to a complex physio-mathematical muscle model. This model is based on macroscopic Hill and microscopic Huxley concepts. The main goal concerns the prediction of the needed pattern stimulation (current and pulse width), which will extend the overall performances and defer the muscle fatigue as much as possible. The controller is mathematically computed and shown to provide satisfactory stability and tracking errors. Its efficiency is illustrated with the control of the knee joint angle under a co-contraction approach.
\end{abstract}

Index Terms-FES, High order sliding mode, closed loop control, non linear system, muscle model.

\section{INTRODUCTION}

Functional electrical stimulation (FES) can help in regaining limited locomotor activities in humans with paraplegia through electrical stimulation of the lower extremity muscles, mainly the quadriceps and hamstrings. Although, open loop control strategies do not account for any changes in the muscles performance such as fatigue or load changes, they are widely used in clinics due to their relative simple implantation [1]. Closed loop controllers, as reported in many studies [2]-[4], use sensor feedback to update the stimulation levels (intensity and pulse width) as a response to any external disturbances. Some authors use a simple PID controller [5], Knee Extension Controller KEC [6], a combination of feedback and feedforward control or an adaptive approach [7]. Others use a first or a second order switching curve in the state space to control patient movements: The On/Off controller [3] and the ONZOFF controller [8], in the so-called "controller-centered" strategies. The main advantage of these strategies is their low number of parameters to be tuned during stimulation. The so-called "subject centered" strategies, (PDMR: PatientDriven Motion Reinforcement [2], CHRELMS: Control by Handle REactions of Leg Muscle Stimulation [4]), introduce the voluntary contribution of the upper body of the patient as an essential part of the control diagram. This later is not yet adopted in clinical use because of the relative high number of parameters to be identified. In order to overcome for the mentioned drawbacks, a better understanding of the muscle element as well as finding a compromise between a complex control strategy and a satisfactory one, should be taken into account. To accomplish this task, a new mathematical muscle model, has been developed [9], representing the complex physiological process. The number of recruited motor units increase as a function of both intensity stimulation $I$ and Pulse Width $P W$. This phenomenon is modeled by an activation model (representing the ratio of recruited fibers $\alpha$ and the chemical control input $u_{c h}$ ) and a mechanical model (muscle contraction) (fig.1). The nonlinearities of the muscle model, and the required robustness regarding parameter variations and external disturbances lead us to adopt a controller relying on the sliding mode theory. The main issue concerns the muscle modeling and its use in the improvement of the human knee movement under FES by means of high order sliding mode controller (HOSM) [10]. In the next section, the system modeling is presented, it includes model of the knee-muscles and its state space formulation. In the third section, the theory of a high order sliding mode controller is presented. The results will be detailed in the fourth section.

\section{System ModelLing}

\section{A. Biomechanical model}

The biomechanical model consists of two segments representing respectively the shank and thigh connected to each other by a revolute joint with one degree of freedom (fig.2). The thigh is supposed fixed with respect to the patient laying supine. Two agonist/antagonist muscles act

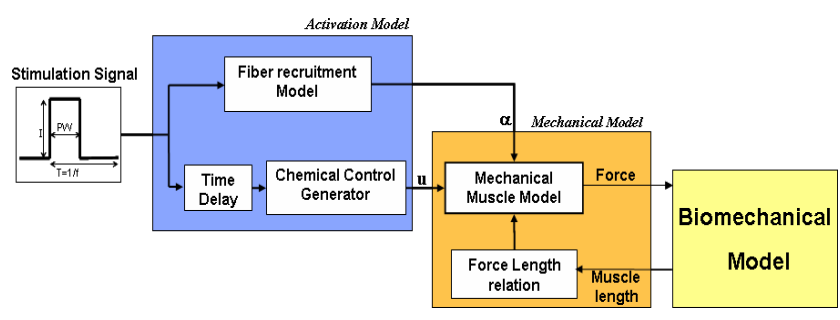

Fig. 1. The muscle model followed by the biomechanical model 


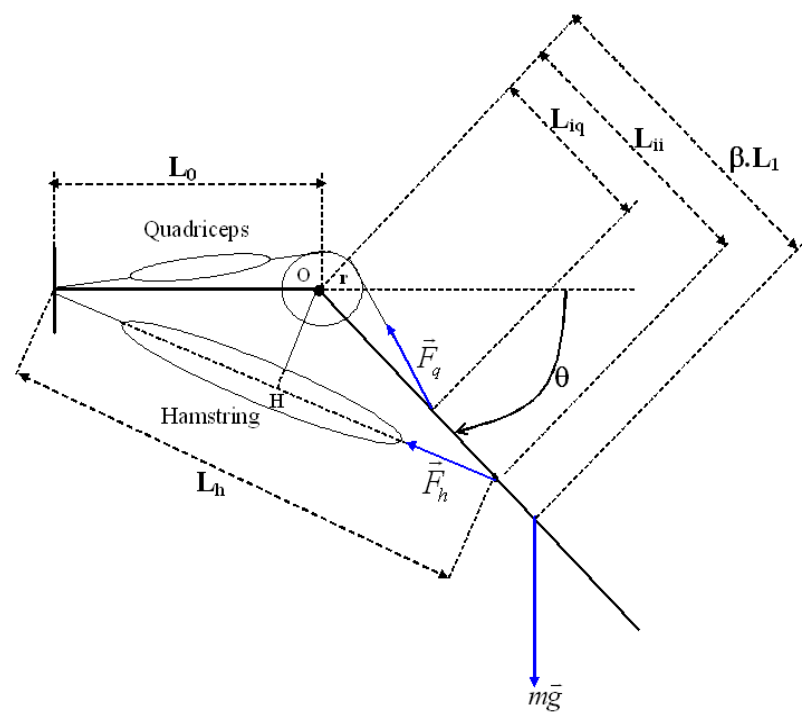

Fig. 2. Biomechanical model of the knee with two muscles

on the knee: the quadriceps acts as an extensor muscle while the hamstrings is the flexor muscle. As a result two forces $F_{q}$ and $F_{h}$ cause respectively the extension and flexion of the knee. $F_{q}$ and $F_{h}$ are the inputs of the biomechanical model while the angle $\Theta$ is the corresponding output. $(\Theta=0$ corresponds to full extension of the knee, $\Theta=150^{\circ}$ corresponds to the maximum flexion and $\Theta=90^{\circ}$ represents the resting position).

- $L_{0}=$ Thigh length,

- $L_{1}=$ Shank length,

- $\mathrm{O}=$ Center of rotation (Knee),

- $L_{i q}=$ Distance between $\mathrm{O}$ and the insertion point of the quadriceps on the shank,

- $L_{i i}=$ Distance between $\mathrm{O}$ and the insertion point of hamstrings on the shank,

- $L_{q}=$ Length of the quadriceps,

- $L_{h}=$ Initial length of the hamstrings,

- $\mathrm{r}=$ Pulley radius,

- $\mathrm{H}=$ Orthogonal projection of $\mathrm{O}$ on $\mathrm{Li}$,

- $F_{q}=$ Extension force generated by the quadriceps,

- $F_{h}=$ Flexion force generated by the hamstrings,

- $\mathrm{G}=$ Gravity force vector,

- $\mathrm{m}=$ Mass of the shank.

The geometric constraints allow us to evaluate quadriceps length $L_{q}$ depending on the knee angle variable $\Theta$ :

$$
L_{q}(\Theta)=\sqrt{L_{0}^{2}-r^{2}}+r \Theta+\sqrt{L_{i q}^{2}-r^{2}}
$$

And the hamstrings length $L_{h}(\Theta)$ :

$$
L_{h}(\Theta)=\sqrt{L_{0}^{2}+L_{i i}^{2}+2 L_{0} L_{i i} \cos (\Theta)}
$$

From the above equations, we can deduce the relative elongations of the quadriceps and the hamstrings:

$\varepsilon_{q}(\Theta)=\frac{L_{q}-L_{0 q}}{L_{0 q}}=\frac{\sqrt{L_{0}^{2}-r^{2}}+r \Theta+\sqrt{L_{i q}^{2}-r^{2}}-L_{0 q}}{L_{0 q}}$
$\varepsilon_{h}(\Theta)=\frac{L_{h}-L_{0 h}}{L_{0 h}}=\frac{\sqrt{L_{0}^{2}+L_{i i}^{2}+2 L_{0} L_{i i} \cos (\Theta)}-L_{0 h}}{L_{0 h}}$

$L_{0 q}$ and $L_{0 h}$ correspond respectively to the initial quadriceps and hamstrings lengths. Moment arm of the quadriceps is supposed to be constant and equal to the pulley radius while the moment arm of the hamstrings depends on the variable angle $\Theta$.

$$
\overline{O H}=\frac{L_{0} L_{i i} \sin (\Theta)}{\sqrt{L_{0}^{2}+L_{i i}^{2}+2 L_{0} L_{i i} \cos (\Theta)}}
$$

From the above equations and the equation of motion which is a second order nonlinear dynamical equation, we obtained the acceleration $\ddot{\Theta}$ as a function of the inertia around the knee joint (I).

$$
\begin{array}{r}
\ddot{\Theta}=\frac{1}{\mathbf{I}}\left[r F_{q}-m g \cos (\Theta) \beta L_{1}-F_{v} \dot{\Theta}\right. \\
\left.-\frac{L_{0} L_{i i} \sin (\Theta)}{\sqrt{L_{0}^{2}+L_{i i}^{2}+2 L_{0} L_{i i} \cos (\Theta)}} F_{h}\right]
\end{array}
$$

Parameters of the above model were taken for an average person: $L_{0}=50 \mathrm{~cm}, L_{i q}=4 \mathrm{~cm}, L_{i i}=5 \mathrm{~cm}, r=$ $1 \mathrm{~cm}, F_{v}=0.5 \mathrm{~N} . \mathrm{m} . \mathrm{s}, I=0.0476 \mathrm{~N} . \mathrm{m} . \mathrm{s}^{2}, \mathrm{~g}=$ $9.8 \mathrm{~N} . \mathrm{m}^{-2}, m=3.5 \mathrm{Kg}$. $\beta$ corresponds to the position of the center of gravity of the shank $(<1), F_{v}$ corresponds to coefficient of viscous friction.

\section{B. Muscle model}

In previous papers [9], [11], a new physiological skeletal muscle model has been proposed to describe the complex internal physiological phenomena. This model was developed in this current study to fulfill most of the physiological processes occurring during the phases of contraction and relaxation. We have adopted this model, in order to develop strategies for simulation, motion synthesis and motor control during clinical restoration of movement. Figure 3 shows the model with the parallel element $E_{p}$ and two elements in series $E_{s}$ (elastic element) and $E_{c}$ (contractile element). This model is controlled by two variables: $u_{c h}$, a chemical control input and $\alpha$, the ratio of the recruited fibers. We have described this model by two differential equations where the outputs are $K_{c}$ and $F_{c}$ representing, respectively, the stiffness and the force generated by the contractile element. $K_{0}$ and $F_{0}$ are the maximum values of $K_{c}$ and $F_{c}$.

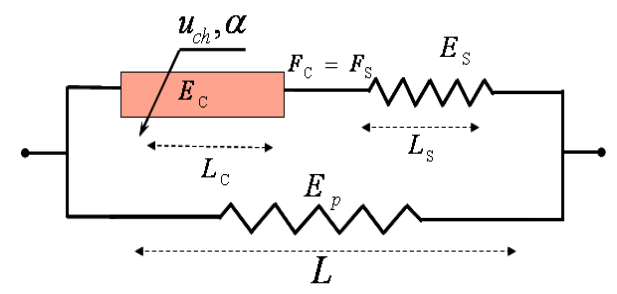

Fig. 3. Muscle model and particularization of EC $\left\{\begin{aligned} \dot{K}_{c}= & \left(s_{0} \alpha K_{0}-s_{u} K_{c}+s_{v} q \frac{s_{0} \alpha F_{0} K_{c}-s_{u} F_{c} K_{c}}{1+p K_{c}-s_{v} q F_{c}}\right) u \\ & -\frac{s_{v} a K_{c}}{1+p K_{c}-s_{v} q F_{c}} \\ \dot{F}_{c}= & \left(\frac{s_{0} \alpha F_{0}-s_{u} F_{c}}{1+p K_{c}-s_{v} q F_{c}}\right) u+\left(\frac{b K_{c}-s_{v} a F_{c}}{1+p K_{c}-s_{v} q F_{c}}\right) \dot{\epsilon}\end{aligned}\right.$ 


$$
\begin{gathered}
s_{u}=\operatorname{sign}(u)=\left\{\begin{array}{lll}
-1 & \text { if } & u<0 \\
+1 & \text { if } & u>0
\end{array}\right. \\
s_{v}=\operatorname{sign}\left(\dot{\epsilon}_{c}\right)=\left\{\begin{array}{lll}
+1 & \text { if } & \dot{\epsilon}_{c}>0 \\
-1 & \text { if } & \dot{\epsilon}_{c}<0
\end{array}\right.
\end{gathered}
$$

$$
s_{0}=\frac{1+s_{u}}{2} \quad a=\frac{L_{0}}{L_{c 0}} \quad b=L_{0} \quad p=\frac{1}{K_{s}} \quad q=\frac{1}{L_{c 0} K_{s}}
$$$$
\epsilon_{c}=\frac{L_{c}-L_{c 0}}{L_{c 0}} \quad \epsilon_{s}=\frac{L_{s}-L_{s 0}}{L_{s 0}} \quad \epsilon=\frac{L-L_{0}}{L_{0}} \quad L=L_{c}+L_{s}
$$

where $s_{u}, s_{0}$ and $s_{v}$ are the signs of the control and the velocities of the contractile element, $L_{c}$ and $L_{s}$ represent respectively the length of the contractile and the elastic elements. The ratio of recruited fibers $\alpha$ is considered as a global scale factor which gives the percentage of the maximal possible force which can be generated by the muscle. Identification of the muscle parameters is ongoing and the simulations performed on the present version of the muscle model show satisfactory accuracy and prediction. The input signal for the muscle model represents the actual electrical signal as provided by the stimulator "PROSTIM" [12] offering the possibility of tuning three independent parameters: amplitude, pulse width and frequency. The parameters of the muscles were taken from [13] as follow:

\begin{tabular}{|c|c|c|c|}
\hline $\begin{array}{c}\text { Muscle model } \\
\text { parameters }\end{array}$ & Variable & $\begin{array}{c}\text { Numeric value } \\
\text { (quad.-hamst.) }\end{array}$ & Unit \\
\hline stiffness of $E_{s}$ & $K_{s}$ & $1.10^{4}$ & $\mathrm{~N} / \mathrm{m}$ \\
\hline $\begin{array}{c}\text { Contractile element } \\
\text { length } E_{c}\end{array}$ & $L_{c 0}$ & $41.10^{-2}, 38.10^{-2}$ & $\mathrm{~m}$ \\
\hline $\begin{array}{c}\text { Elastic element } \\
\text { length } E_{s}\end{array}$ & $L_{s 0}$ & $8.10^{-2}, 10.10^{-2}$ & $\mathrm{~m}$ \\
\hline
\end{tabular}

\section{Muscle-Knee: State space Model}

The model of the muscles and knee joint can be rewritten as a non-linear state space function:

$$
\dot{\mathbf{X}}=\mathbf{f}(\mathbf{x}, \mathbf{t}, \mathbf{U})
$$

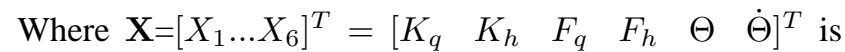
the state vector and $\mathbf{U}=\left[\begin{array}{llll}u_{q} & \alpha_{q} & u_{h} & \alpha_{h}\end{array}\right]^{T}$ the control vector. The variable $\Theta$ represents the joint knee angle. The state variables $K_{q}, F_{q}, u_{q}, \alpha_{q}$ and $K_{h}, F_{h}, u_{h}, \alpha_{h}$ are respectively the state variables of the quadriceps and hamstrings. The state space model of the knee joint can be expressed as:

$$
\begin{aligned}
\dot{X}_{1}= & \left(s_{0 q} \alpha_{q} K_{0 q}+s_{v q} q_{q} \frac{s_{0 q} \alpha_{q} F_{0 q} X_{1}-s_{u q} X_{3} X 1}{1+p_{q} X_{1}-s_{v q} q_{q} X_{3}}\right) u_{q} \\
& -\frac{s_{v q} \alpha_{q} X_{1} r X_{6}}{L_{0 q}+p_{q} X_{1}-s_{v q} q_{q} X_{3}}-s_{u q} X_{1} u_{q} \\
\dot{X}_{2}= & \left(s_{0 h} \alpha_{h} K_{0 h}+s_{v h} q_{h} \frac{s_{0 h} \alpha_{h} F_{0 h} X_{2}-s_{u h} X_{4} X_{2}}{1+p_{h} X_{2}-s_{v h} X_{2} X_{4}}\right) u_{h} \\
& -\frac{s_{v h} a_{h} X_{2} L_{0} L_{i i} \sin \left(X_{5}\right)}{L_{0 h} \sqrt{L_{0}^{2}+L_{i i}^{2}+2 L_{0} L_{i i} \cos \left(X_{5}\right)}\left(1+p_{h} X_{2}-s_{v h} q_{h} X_{4}\right)} \\
& -s_{u h} X_{2} u_{h}
\end{aligned}
$$

$$
\begin{aligned}
\dot{X}_{3}= & \frac{s_{0 q} \alpha_{q} F_{0 q}-s_{u q} X_{3}}{1+p_{q} X_{1}-s_{v q} q_{q} X_{3}} u_{q}-\frac{b_{q} X_{1}-s_{v q} a_{q} X_{3} r X_{6}}{L_{0 q}\left(1+p_{q} X_{1}-s_{v q} q_{q} X_{3}\right)} \\
\dot{X}_{4}= & -\frac{b_{h} X_{2}-s_{v h} a_{h} X_{4} L_{0} L_{i i} \sin \left(X_{5}\right)}{L_{0 h} \sqrt{L_{0}^{2}+L_{i i}^{2}+2 L_{0} L_{i i} \cos \left(X_{5}\right)\left(1+p_{h} X_{2}-s_{v h} q_{h} X_{4}\right)}} \\
& +\frac{s_{0 h} \alpha_{h} F_{0 h}-s_{u h} X_{4}}{1+p_{h} X_{2}-s_{v h} q_{h} X_{4}} u_{h} \\
\dot{X}_{5}= & X_{6} \\
\dot{X}_{6}= & \frac{1}{I}\left(X_{3} r-X_{4} \frac{L_{0} L_{i i} \sin \left(X_{5}\right)}{\sqrt{L_{0}^{2}+L_{i i}^{2}+2 L_{0} L_{i i} \cos (\Theta)}}-F_{v} X_{6}\right. \\
& \left.-m g \cos X_{5} \beta L_{1}\right)
\end{aligned}
$$

\section{Sliding MOde CONTROLler}

The sliding mode control, has become recently widely used due to its high accuracy and robustness with respect to parameters uncertainty disturbances. The control task is to keep a constraint, given by equality of a smooth function called sliding surface, to zero. The dynamic smoothness in the vicinity of the sliding mode represents the sliding order of the system. As a generalisation of the classical sliding mode, this notion has been extended to the high order sliding mode. In this case, the control acts on the higher order time derivatives of the sliding variable instead of acting on its first time derivative. Thus the discontinuity of the control vector does not appear in the first $(r-1)^{t h}$ total time derivative.

$$
\frac{\partial s^{(i)}}{\partial u}=0,(i=1,2, \ldots, r-1), \frac{\partial s^{(r)}}{\partial u} \neq 0
$$

$\mathrm{s}, \mathrm{r}$ represent respectively the sliding surface and the relative degree. $u$ is the resulting control vector. Consequently we have:

$$
s=\dot{s}=\ddot{s}=\ldots=s^{r-1}=0
$$

\section{A. Position control law strategy}

The sliding surface used to constraint the dynamic behavior of the knee joint is a first order differential equation chosen as:

$$
s=\left(\dot{\Theta}_{d}-\dot{\Theta}\right)+\lambda\left(\Theta_{d}-\Theta\right)
$$

Where $\dot{\Theta}_{d}, \Theta_{d}$ are respectively the desired velocity and desired position, $\lambda$ is a positive coefficient. Higher values of $\lambda$, lead to a faster convergence along the sliding surface to the zero point of the phase-plane. Let us consider the sliding surface equation (3) in order to determine the relative order of the controlled system. We obtain the following result:

$$
\frac{\partial \dot{s}}{\partial u}=0, \frac{\partial \ddot{s}}{\partial u} \neq 0
$$

Therefore, the relative degree of the sliding mode control is $r=2$. Considering the step response case $\left(\ddot{\Theta}_{d}=\dot{\Theta}_{d}=0\right)$, the second time order derivative of the sliding surface can be written as:

$$
\ddot{s}=-\ddot{X}_{6}-\lambda \dot{X}_{6}
$$


The expression of the second time derivative of the state variable $X_{6}$ is given by:

$$
\begin{aligned}
& \frac{r s_{0 q} \alpha_{q} F_{0 q}}{1+p_{q} X_{1}-s_{v q} q_{q} X_{3}} u_{q}-\frac{r s_{0 q} X_{3}}{1+p_{q} X_{1}-s_{v q} q_{q} X_{3}} u_{q} \\
& +r \frac{b_{q} X_{1}-s_{v q} a_{q} X_{3} r X_{6}}{L_{0 q}\left(1+p_{q} X_{q}-s_{v q} q_{q} X_{3}\right)} \\
& -\frac{s_{0 h} \alpha_{h} F_{0 h} L_{0} L_{i i} \sin \left(X_{5}\right)}{\left(1+p_{h} X_{2}-s_{v h} q_{h} X_{4}\right) \sqrt{L_{0}^{2}+L_{i i}^{2}+2 L_{0} L_{i i} \cos \left(X_{5}\right)}} u_{h} \\
& +\frac{s_{0 h} X_{4} L_{0} L_{i i} \sin \left(X_{5}\right)}{\left(1+p_{h} X_{h}-s_{v h} q_{h} X_{4}\right) \sqrt{L_{0}^{2}+L_{i i}^{2}+2 L_{0} L_{i i} \cos \left(X_{5}\right)}} u_{h} \\
& \ddot{X}_{6}=\frac{1}{I}[ \\
& -\frac{\left(b_{q} X_{1}-s_{v q} a_{q} X_{3}\right) r X_{6} L_{0} L_{i i} \sin \left(X_{5}\right)}{L_{0 q}\left(1+p_{q} X_{1}-s_{v q} q_{q} X_{3}\right) \sqrt{L_{0}^{2}+L_{i i}^{2}+2 L_{0} L_{i i} \cos \left(X_{5}\right)}} \\
& -X_{4} \frac{L_{0} L_{i i} X_{6} \cos \left(X_{5}\right) \sqrt{L_{0}^{2}+L_{i i}^{2}+2 L_{0} L_{i i} \cos \left(X_{5}\right)}}{L_{0}^{2}+L_{i i}^{2}+2 L_{0} L_{i i} \cos \left(X_{5}\right)} \\
& -X_{4} \frac{L_{0}^{2} L_{i i}^{2} \sin ^{2}\left(X_{5}\right)}{\left(L_{0}^{2}+L_{i i}^{2}+2 L_{0} L_{i i} \cos \left(X_{5}\right)\right) \sqrt{L_{0}^{2}+L_{i i}^{2}+2 L_{0} L_{i i} \cos \left(X_{5}\right)}} \\
& \left.+m g \beta L_{1} X_{6} \sin \left(X_{5}\right)-F_{v} \dot{X}_{6}\right]
\end{aligned}
$$

Inserting the expressions of $\dot{X}_{6}$ and $\ddot{X}_{6}$ within equation (5) allows writing the second time derivative of $s$ as:

$$
\ddot{s}=\varphi(x, t)+\gamma(t, x) u
$$

It is assumed that $\Phi>0,|\varphi| \leq \Phi, 0<\Gamma_{m} \leq \gamma \leq$ $\Gamma_{M}$ [14], where $s_{0}, u_{0}<1, \Gamma_{m}, \Gamma_{M}$ and $\Phi$ are positive constants.

We express the equation (7) as:

$$
\left\{\begin{array}{l}
\dot{y}_{1}=y_{2} \\
\dot{y}_{2}=\varphi(x, t)+\gamma(t, x) u
\end{array}\right.
$$

Where $y_{1}=s$. In that case, the problem is equivalent to the finite time stabilization problem for the uncertain secondorder system.

\section{B. Statement of the control algorithm}

[14] presented a range of 2-sliding algorithms to stabilise second order uncertain nonlinear systems. In the current study we have implemented the algorithm with prescribed law of variation of the sliding surface. This choice has been made based on criteria of robustness and finite time convergence [10]. The general formulation of such a class of a sliding mode control algorithm is:

$$
\dot{u}=\left\{\begin{array}{ccc}
-u & \text { if } & |u|>1 \\
-V_{M} \operatorname{sign}\left(y_{2}-g_{c}\left(y_{1}\right)\right) & \text { if } & |u| \leq 1
\end{array}\right.
$$

Where $V_{M}$ is a positive constant and $g_{c}$ a continuous function (Fig.4). Moreover, this function must verify some specific conditions (see [10]).

$$
g_{c}\left(y_{1}\right)=-\lambda_{1}\left|y_{1}\right|^{\rho} \operatorname{sign}\left(y_{1}\right), \quad \lambda_{1}>0,0.5 \leq \rho<1
$$

The sufficient condition for the finite time convergence to the sliding manifold is defined by the following inequality:

$$
V_{M}>\frac{\Phi+\sup \left[\dot{g}_{c}\left(y_{1}\right) g_{c}\left(y_{1}\right)\right]}{\Gamma_{m}}
$$

Larger values of $\lambda_{1}$ accelerate the convergence to reach the sliding surface and provide better robustness and stability. A substitution of $y_{2}$ by $\Delta y_{1}$ is theoretically possible whether $y_{2}$ is not available.

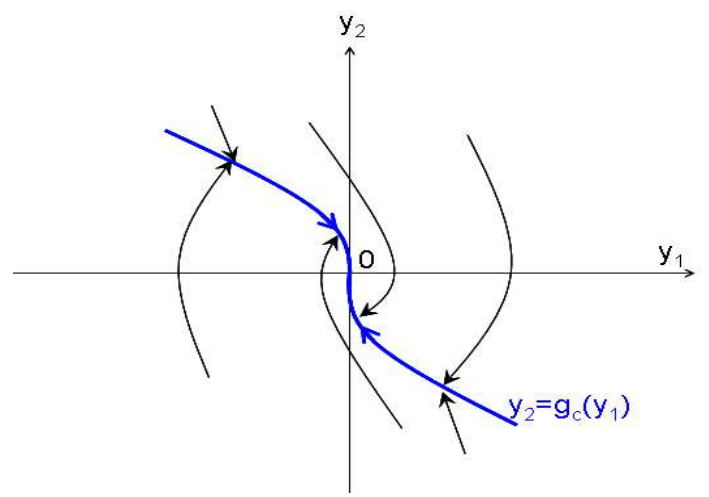

Fig. 4. Phase plot of the prescribed law convergence algorithm

\section{CO-CONTRACTION RESUlTS}

We have implemented the control algorithm defined by equation $(8)$ on the simulator of the biomechanical model of the knee joint $(c f$. equation $(6))$. The components of the control vector $U$ are the chemical inputs $\left(u_{q}, u_{h}\right)$ and the ratio of the recruited fibers $\left(\alpha_{q}, \alpha_{h}\right)$. These coefficients depend on the electrical stimulation current and Pulse Width modulation values, In our case the biomechanical model of the knee joint is controlled by two muscles: quadriceps and hamstrings. Consequently, there are two electrical currents, $I_{q}$ and $I_{h}$ as well as two Pulse Width Modulations values, (see [15]) $P W_{q}$ and $P W_{h}$ which have to be deduced from the control vector $u$. Muscle co-contraction can be defined as the simultaneous activation of agonist and antagonist muscle groups crossing the same joint and acting in the same plane [16]. The opposite muscles, quadriceps and hamstrings in this case, act simultaneously and thereby increase the stiffness at the knee joint. According to the state-space of the muscle-knee model (section $I V$ ), a co-contraction effect would increase $\dot{X}_{3}$ and $\dot{X}_{4}$, which will ensure a safer movement of the shank. Therefore, we propose a method to define the contribution of the control vector $u$ stemming from the 2-sliding controller to calculate the needed electrical current stimulation values. According

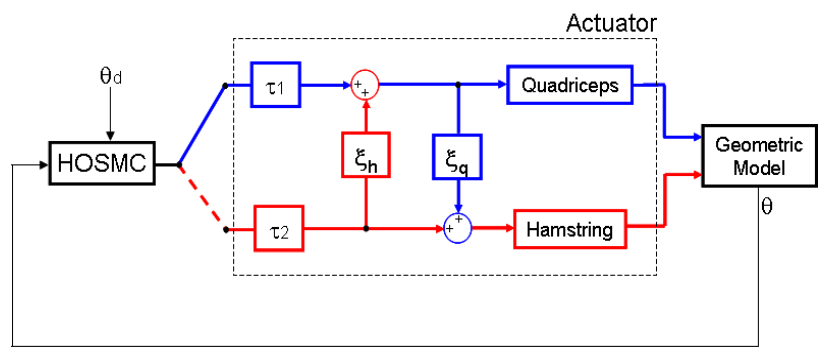

Fig. 5. Co-contraction of the two muscles: quadriceps and hamstrings

to the sign of the resulting control variable $(u)$ at the 
output of the HOSM Controller ( $f g .5$ ), we have chosen to stimulate whether the quadriceps or the hamstrings. The co-contraction phenomenon was represented by a simultaneous contraction of the muscle and its antagonist muscle via a static ponderation $\xi_{q}, \xi_{h}$ respectively for quadriceps and hamstrings.

$$
\begin{aligned}
& I f(u>0) \Rightarrow\left\{\begin{array}{llc}
I_{q} & = & \frac{u}{u_{\text {nom }}} I_{\text {Max }} \\
I_{h} & = & \xi_{q} I_{q}
\end{array}\right. \\
& \operatorname{If}(u<0) \Rightarrow\left\{\begin{array}{llc}
I_{q} & = & \xi_{h} I_{h} \\
I_{h} & = & \frac{u}{u_{\text {nom }}} I_{\text {Max }}
\end{array}\right.
\end{aligned}
$$

$u_{n o m}$ and $I_{M a x}$ correspond respectively to nominal value of the control $u$ and the maximal value authorized to stimulate a muscle (around $200 \mathrm{~mA}$ ). The current values for quadriceps $I_{q}$ and hamstrings $I_{h}$ and the Pulse Width, respectively $P W_{q}$ and $P W_{h}$, enable us to evaluate the required ratios of fibers to be recruited $\left(\alpha_{q}, \alpha_{h}\right)$. The control vector $u$ is defined as:

$$
u=-\int V_{M} \operatorname{sign}\left(y_{2}-g_{c}\left(y_{1}\right)\right) d t \quad(\text { if }|u| \leq 1)
$$

The chemical inputs $u_{q}$ and $u_{h}$ are automatically activated when the electrical currents are respectively superior to zero. We have implemented this algorithm on the simulator built with Simulink ${ }^{T M}$ software. We applied two different desired positions, starting from the rest position, $\Theta_{d}=90^{\circ}$ as:

$$
\left\{\begin{array}{l}
\text { 1) } 1 s<t<4 s: \quad \Theta_{d}=130^{\circ} \\
\text { 2) } 6 s<t<9 s: \Theta_{d}=50^{\circ} \\
3) \quad \text { Otherwise: } \Theta_{d}=90^{\circ}
\end{array}\right.
$$

The coefficient of the 2-sliding controller were chosen to verify the condition equations $(9)$. The following values have been used: $\lambda=10, \lambda_{1}=20, \rho=0.7, V_{M}=1$. The simulation sampling periode was set to $10^{-4} \mathrm{sec}$. Figure $6(a)$ shows the step response for different desired angles. We notice in Fig. 6(b) the finite time convergence of the sliding surface about $1 \mathrm{sec}$ in knee flexion and extension. Desired and current angle curves match when sliding surface reaches zero. In Fig. 7 (a), we show the resulting simultaneous stimulation currents for quadriceps and hamstrings $I_{q}$ and $I_{h}$. Fig. $7(b)$ presents the control vector $u$ computed by the equation (13).

If the resulting control variable $u$ is positive (respectively negative) the quadricep (respectively hamstrings) is stimulated and controlled in a closed loop as shown in (Fig.5), while its antagonist muscle is controlled in an open loop control scaled by $\xi_{q}$ (respectively $\xi_{h}$ ). The resulting control variable $u$ was scaled, according to its sign by $\tau_{1}$ (respectively $\tau_{2}$ ) to the normalized amplitude of the current stimulation. Simulation results in Fig.8 shows the alternative contraction of both quadriceps and hamstrings by setting $\xi_{q, h}$ to 0 forming thus, the On-Off control. Fig. 9 shows the sliding mode controller tracking a real joint angle trajectory recorded when walking at natural cadence [18]. The desired and the actual curves match very well. Parameters of the muscle model were identified by experiments on paraplegic patient fig. 10 .
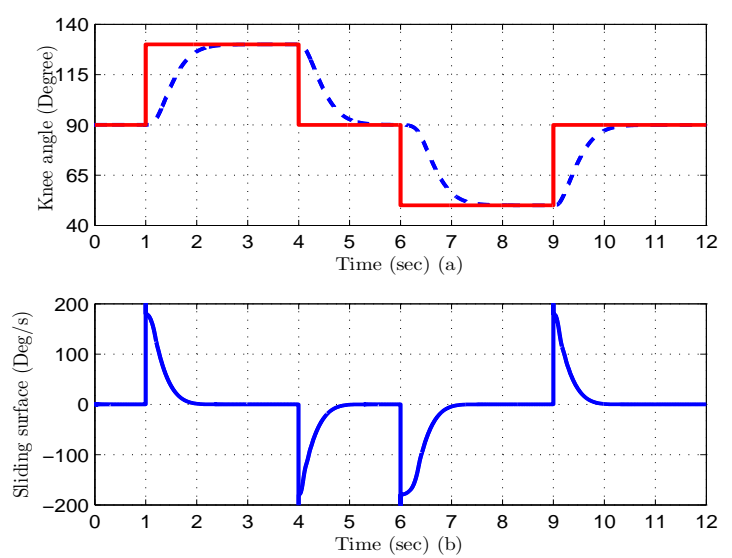

Fig. 6. a) Desired step and actual knee angle variation, b) stabilization of the sliding surface
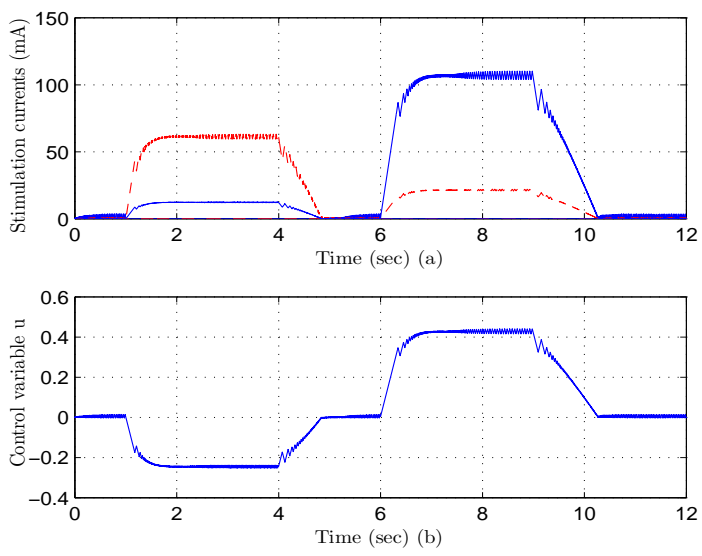

Fig. 7. a) Stimulation current $\left(. . I_{h},-I_{q}\right) \xi_{q}=\xi_{h}$, b) The resulted control vector $\mathrm{u}$
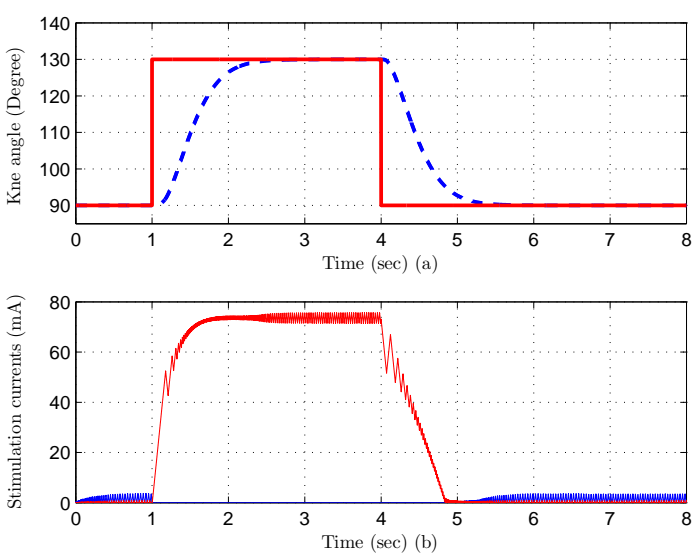

Fig. 8. a) Desired step and actual knee angle variation, b) Stimulation current $\left(-I_{h}, . . I_{q}\right)$ 


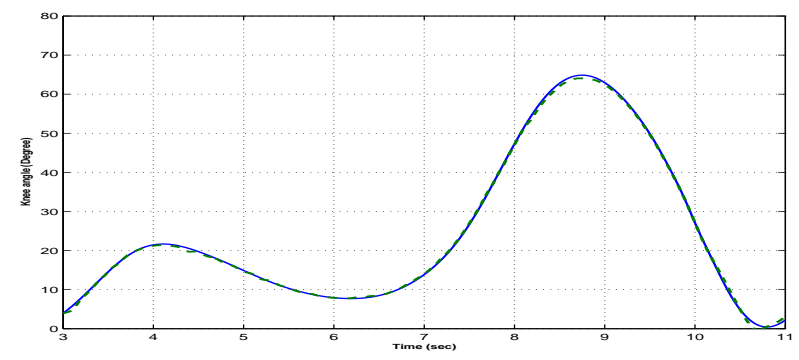

Fig. 9. Experimental and actual Knee angle variation recorded during a complete walking phase

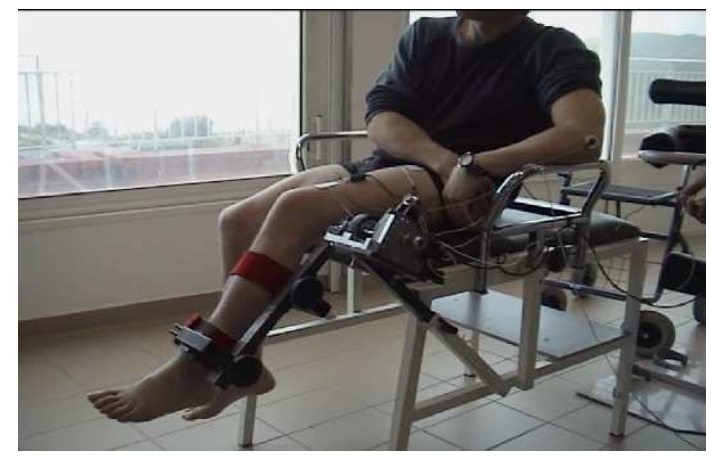

Fig. 10. Experiments on paraplegic patient during knee angle and torque measurements were performed at the Centre Bouffard-Vercelli (Cerbere France)

\section{CONCLUSION}

Few studies have treated the human muscle as an entire physiological element. Known by their robustness and accuracy, we used the sliding mode control. Because of the nonlinearity and the presence of a 2-order sliding system we adopted, in the current study, a high order sliding mode controller HOSM, which seems necessary to ensure a robust control and a safer movement of the lower extremities. This later was applied to a new multi-scale model developed within the $D E M A R$ project. The muscle model is based on internal physiological characteristics assembling two levels: the microscopic one, involving the sliding actin-myosin filaments and the macroscopic part represented by a contractile element and an elastic element. We were able to control two antagonist muscles quadriceps and hamstrings alternatively and simultaneously (the so called co-contraction effect) with the same control vector, forcing dynamically the system to behave as a first order response. Satisfactory stability and tracking error were achieved after a finite time delay. The controller was able to track also a pre-recorded knee angle variation during a complete gait cycle. In order to validate simulation results further work will be carried out with paraplegic patients to evaluate the accuracy and the robustness of the high order sliding controller. Experiments are ongoing to validate the 2-sliding controller by using a multi-moment platform on a paraplegic patient. Other control strategies will be implemented as well to analyze the relevance of the muscle model in much complex situations.

\section{ACKNOWLEDGMENT}

Many thanks to all DEMAR members who provided all supports, substantive feedback and great contribution to the present work. This work is supported by the MIMES RNTS national grant.

\section{REFERENCES}

[1] Bajd T, Kralj A, et al. Use of a two-channel functionnal electrical stimulator to stand paraplegics. Physical therapy, 61:526-527,1981

[2] Riener R, Fuhr T, "Patient-Driven Control of FES-Supported standing Up: A simulation study." IEEE Transactions on rehabilitation engineering, Vol 6, N.2 June 1998 pp.113-123.

[3] Mulder A., Veltink P., Boom H. "On/off control in FES-induced standing up:a model study and experiments." Med. and Biol. Eng. and Comput.,1992, 30, 205-212.

[4] Donaldson N., Yu C. "FES standing control by handle reactions of leg muscle stimulation (CHRELMS)" IEEE Transactions on rehabilitation engineering, Vol 4 pp.280-284, 1996.

[5] Wood D., Harper V. et al. "Experience in Using Knee angles as part of a closed-Loop Algorithm to control FES-Assisted Paraplegic Standing." 6th Vienna International Workshop on Functional Electrical Stimulation. 137-140, 1998.

[6] Poboroniuc, M.; Wood, D.; Donaldson, N.; Fuhr, T.; Riener R.: Closed-loop control for FES-based restoration of standing in paraplegia. -In: ISPRM 2003, submitted

[7] Ferrain M, Palazzo F, Riener R. " Model-Based Control of FESInduced Single Joint Movements" IEEE Trasactions on Neural systems and rehabilitation engineering, Vol.9, NO.3, September 2001.

[8] Poboroniuc M., T. Fuhr et al. "FES-Induced Standing-Up and sitting down control strategies in Paraplegia", FESnet 2002.

[9] El Makssoud H., Guiraud D., Poignet P., Mathematical muscle model for Electrical Stimulation control strategies IEEE International Conference on Robotics and Automation New Orleans, LA, USA, April 26 May 1, 2004.

[10] L. Fridman, A. Levant, "High-Order Sliding Modes", Sliding Modes Control in Engineering, Ed. W. Perruquetti, J.P. Barbot, Marcel Dekker, Inc. New-York, pp. 53-101, 2002.

[11] El Makssoud H., Mohammed S., Fraisse P., Guiraud D and Poignet P. Control of the knee joint under Functional Electrical Stimulation Simulation results based on a new Physiological muscle model, 8th Vienna International Workshop on Functional Electrical Stimulation, Vienna, Austria, 10.Sept. - 13. Sept. 2004.

[12] Guiraud D., Denis B., Couderc P., Taroni G., Stieglitz T. Description of a sixteen-channel FES implantable system, IFESS2000 5th conference, Aalborg, Danemark, 18-24 juin, p292-294.

[13] Kromer V. Analyse des forces musculaires au cours de la marche Approche en corps rigide et simulation en mecanismes plans flexibles par elements finis, Thesis at I.N.P.L. 1993

[14] Levant A.,"Sliding order and sliding accuracy in sliding model control" International Journal of Control, Vol.58 No.6, pp.1247-1263, 1993.

[15] El Makssoud H., Guiraud D., Poignet P., Enhancement of physiological and mechanical modelling of the skeletal muscle controlled by Functional Electrical Stimulation, 9th IFES Society, September 2004, Bournemouth, UK.

[16] Onley SJ. Quantitative evaluation of cocontraction of knee and ankle muscles in normal walking. In Winter DA, Norman RW, Wells RP, Hayes KC, Patla AE, (Eds) Biomechanics IX-A Champain IL: Human Kinetics; 1985: p.431-7.

[17] Veltink P, Chizeck H, et al. "Nonlinear joint angle control for artificially stimulated muscle." IEEE Transactions on biomedical engineering,Vol. 39 N.4, April 1992 pp.368-380.

[18] Winter DA. "Biomechanics and Motor Control of Human Movement" Second edition. New York, John Wiley and Sons, Inc,1990. 